\title{
Enhancing Classroom Performance: A Technology Design To Support The Integration Of Collaborative Learning And Participative Teams
}

\author{
Michael T. Marsh, Shippensburg University \\ Ronald Taylor, Shippensburg University
}

Stephen J. Holoviak, Shippensburg University

\begin{abstract}
Integral components of today's successful business models frequently include information technology, effective collaboration, and participative teamwork among employees. It is in the best interest of students for educators to provide classrooms that reflect a profitable practitioner's environment. Students studying for careers in business should learn the advantages of teamwork and apply what they learn by participating as members of project teams as part of curriculum activities. Organizations are incorporating collaborative hardware, software, and spaces at an unprecedented pace and rapid advancements in technology are continuously changing collaboration and teamwork strategies. To better prepare students to perform in this type of environment, the John L. Grove College of Business at Shippensburg University of Pennsylvania has recently designed and equipped classrooms to support intellectual teamwork activities. The intent of this paper is to share the details regarding the teaching/learning experiences of the faculty and students using the facilities, the physical design of the spaces, and the technology that was incorporated into the designated spaces. The discussion of lessons learned and recommendations for designing and implementing a "real learning for real life" classroom should be particularly useful to institutions planning or actively involved in designing technologyenhanced collaborative or teamwork activity facilities.
\end{abstract}

Keywords: teamwork, collaboration, information technology, classroom organization

\section{INTRODUCTION}



oday, organizations have entered an environment in which turbulence seems to be the norm and change is the only constant. Many factors are forcing businesses to look for new ways to meet market demands quickly and efficiently. These factors include: the need for speed, the need to respond to vast technological changes, the trend toward globalization and increased market pressures (Scholtes, 1996). Clearly, to succeed in this dynamic environment, the knowledge, skills, experience, and perspectives of a wide range of people must be brought together. Thus, the need for teams is evident. Teams create environments in which participant can keep up with needed changes, learn more about the business, and gain skills in collaboration (Scholtes, 1996). Furthermore, one of the top ten attributes that businesses consider when college graduate are being evaluated for employment is the ability to work effectively as a team member. Robinson (2001) found that many job candidates do not have the team skills necessary to function in the environment described above. Consequently, it is a common practice to learn team dynamics on the job for those lacking in team skills. Robinson (2001) further points out the need for formal training in team activities is becoming increasingly necessary, especially for those involving shared intellectual contributions. Schellhardt (1994) strongly recommended business 
schools provide the critical academic training necessary for students to learn team skills so, as new employees, they would be more productive and able to integrate into the organization more easily

Teaching teamwork activities that have intellectual components to students in business classes with more than 10 students frequently requires both innovative teaching strategies and special classroom facilities. Technology enhanced classroom facilities can be used to enhance students' experiences in a number of ways. High tech facilities can be used to give students hands-on experiences with technology currently in use in the business world. Teaching the time-honored standards of team concepts such as building the team; developing team strategies; gathering, analyzing, and distributing information; and critiquing the team experience can be facilitated using classroom facilities designed to support teamwork activities. This paper discusses the experiences of John L. Grove College of Business students in such a classroom and provides recommendations for including instructional technology into the college classroom.

\section{THE TECHNOLOGY ENHANCED CLASSROOM}

The Business Learning Lab (BLL), located in the College of Business, was conceptualized and designed by College faculty and students. Funding for the project was through the State of Pennsylvania Department of Education's Higher Education Technology Grants. The state offered competitive grants for the initiative, Improving Technology at Colleges and Universities (ITCU), designed "to strengthen learning by improving and integrating technology" in higher education curriculum. The Business Learning Lab (BLL) was optimally designed for 32 students, four student stations at each of eight specially designed teamwork stations. Each student has a high end, wireless capable Dell laptop with software appropriate for the various classes conducted in the BLL including Microsoft Windows $^{\circledR}$ and Office, SPSS ${ }^{\circledR}$, SAS ${ }^{\circledast}$, Microsoft Studio.NET ${ }^{\circledR}$, and SynchroEyes ${ }^{\mathrm{TM}}$, a classroom management software. Additional security software is installed to prevent unintended or malicious modifications to the laptop software setting. Technology in the BLL includes the usual array of video and DVD players, a sound system, plasma display, a high lumen projector, and a wireless network. In addition to a desktop pc and typical peripherals, the instructor's station includes a Sympodium ${ }^{\mathrm{TM}}$, by far the favorite teaching tool of instructors using the Lab.



Figure 1 
The feature that ties the technology into an integrated teamwork teaching/learning lab is the custom designed teamwork stations. Working with Thomas Huntz Associates, a commercial furniture manufacture located in Quakertown, PA, (http://www.thafurniture.com), the design team created teamwork stations that both facilitated teamwork activities and performed as traditional classroom desks. During the search for appropriate teamwork stations, the design team found many workstation solutions that were adequate, but none were exactly what were wanted or were not within the grant's budget criteria. The final (proprietary) table design specifications are shown in Figures 1 and 2; they are patterned after the "tulip-shaped" tables used very successfully in Rensselaer Collaborative "Classroom-in-the-Round". (Dugan, 1998; Rogers, 1997) The arrangement of the tables in the room is shown in Figure 3. The workstation design allows easy face-to-face communications among team members while still permitting unimpeded views of the instructor, fixed screen, or plasma display. Photographs of the room are shown in Figures 4, 5, 6 and 7 .
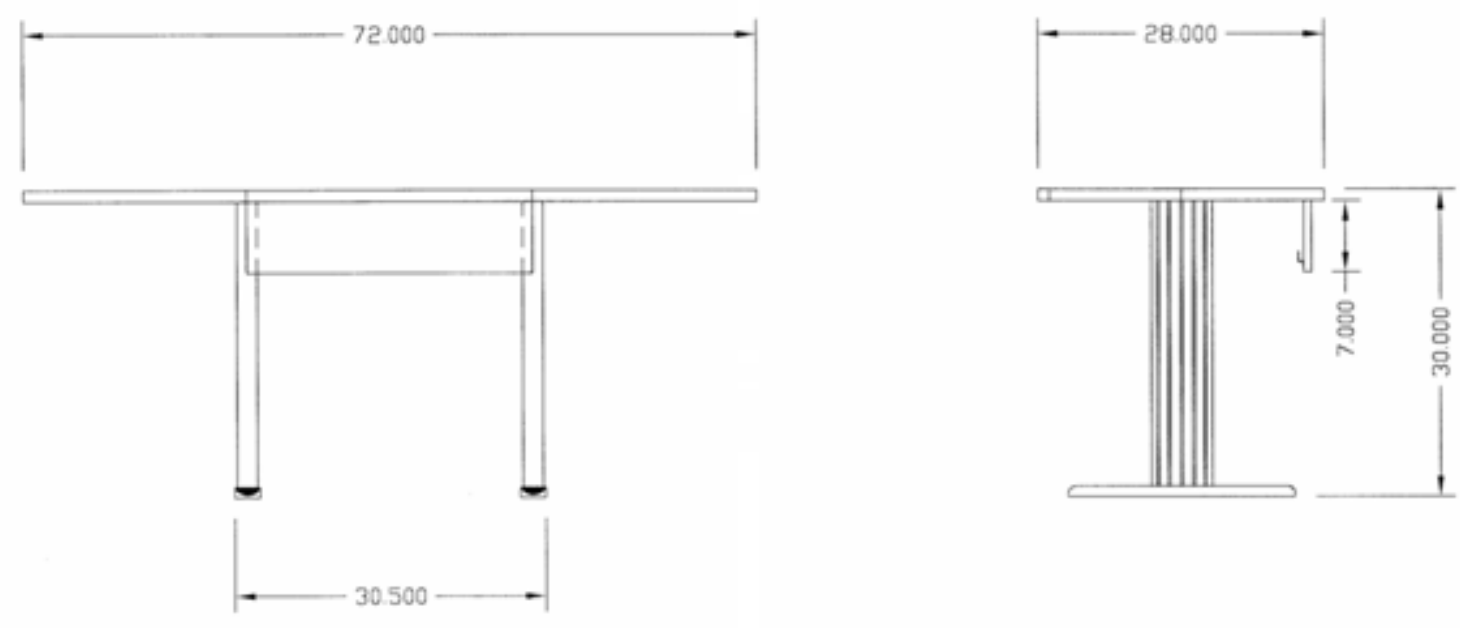

Figure 2

Classroom management software is integral to teamwork exercises and activities. (Manning, 2000) It allows the instructor to exercise considerable control over activities in the classroom. The instructor can lock all computers, form groups, take over control of any student's computer from the instructor's station, observe the screen display of any (or all) computers, and select any computer's display for projection onto the screen. The wireless network and laptops allow considerable flexibility in that student's can physically move to another table or group. Laptops, instead of desktops, also allow a "convertible classroom" since, when the lid is closed and laptop moved aside, the arrangement resembles a traditional classroom with room on the desktop for texts and note taking 




Instructor's

Station

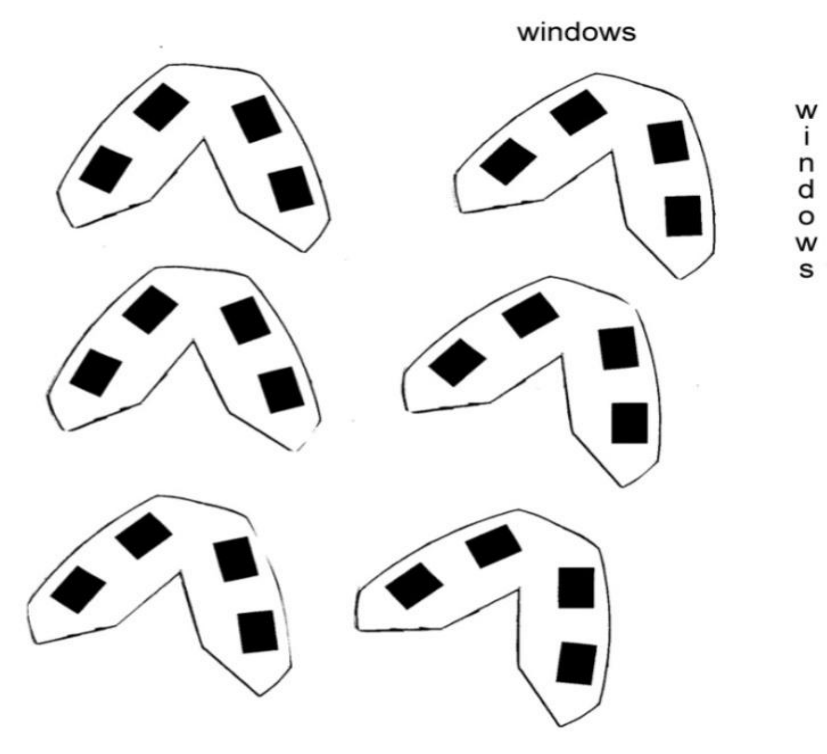

Screen door

Figure 3

\section{INITIAL EXPERIENCES}

Courses from several disciplines in the College of Business were conducted in the new Business Learning Lab. They included Introduction to Business Computer Systems, C++ Programming, Business Information Processing, Marketing Research, Organizational Behavior, and Marketing Analysis and Strategy Development. Data regarding students' experiences in this last course were gathered using a questionnaire given at the end of the semester. Three sections of Marketing Analysis and Strategy Development were offered in the spring semester. Two sections totaling 43 students met in the BLL and one section with 28 students were assigned a traditional classroom having only an instructor's computer and LCD projector. By the end of the semester, students from both classroom expressed strong opinions on how the classroom affected their experience in the course. The students in the traditional classroom generally felt they did not receive the same instruction and experiences their counterparts received in the BLL. In fact the means were significantly different between the two classrooms. The students in the BLL were extremely satisfied and felt they received the best team training in their entire four years. Chart 1 shows the distribution and degree of support students in this marketing course would give towards the designing and equipping the type of classroom they used for the course. Students were also asked to quantify their satisfaction (or dissatisfaction) with the learning environment for the semester. Chart 2 shows the distribution of responses. During end-of-the-semester discussion about the course and classroom setting, students assigned to the traditional classroom were nearly unanimous in their feelings of being "cheated" out of an innovative and enjoyable learning experience by not being able to use the BLL. 


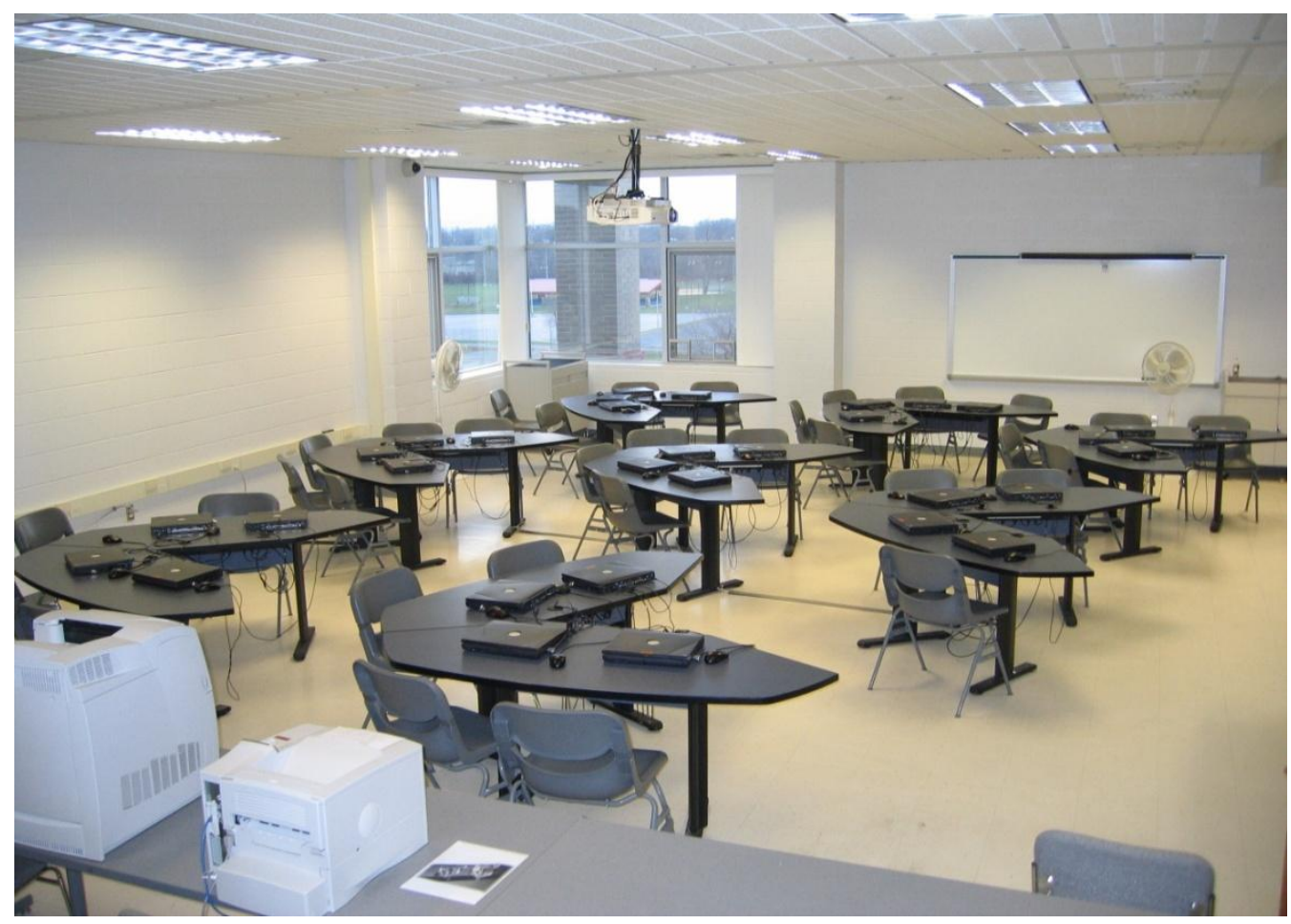

Figure 4



Figure 5 


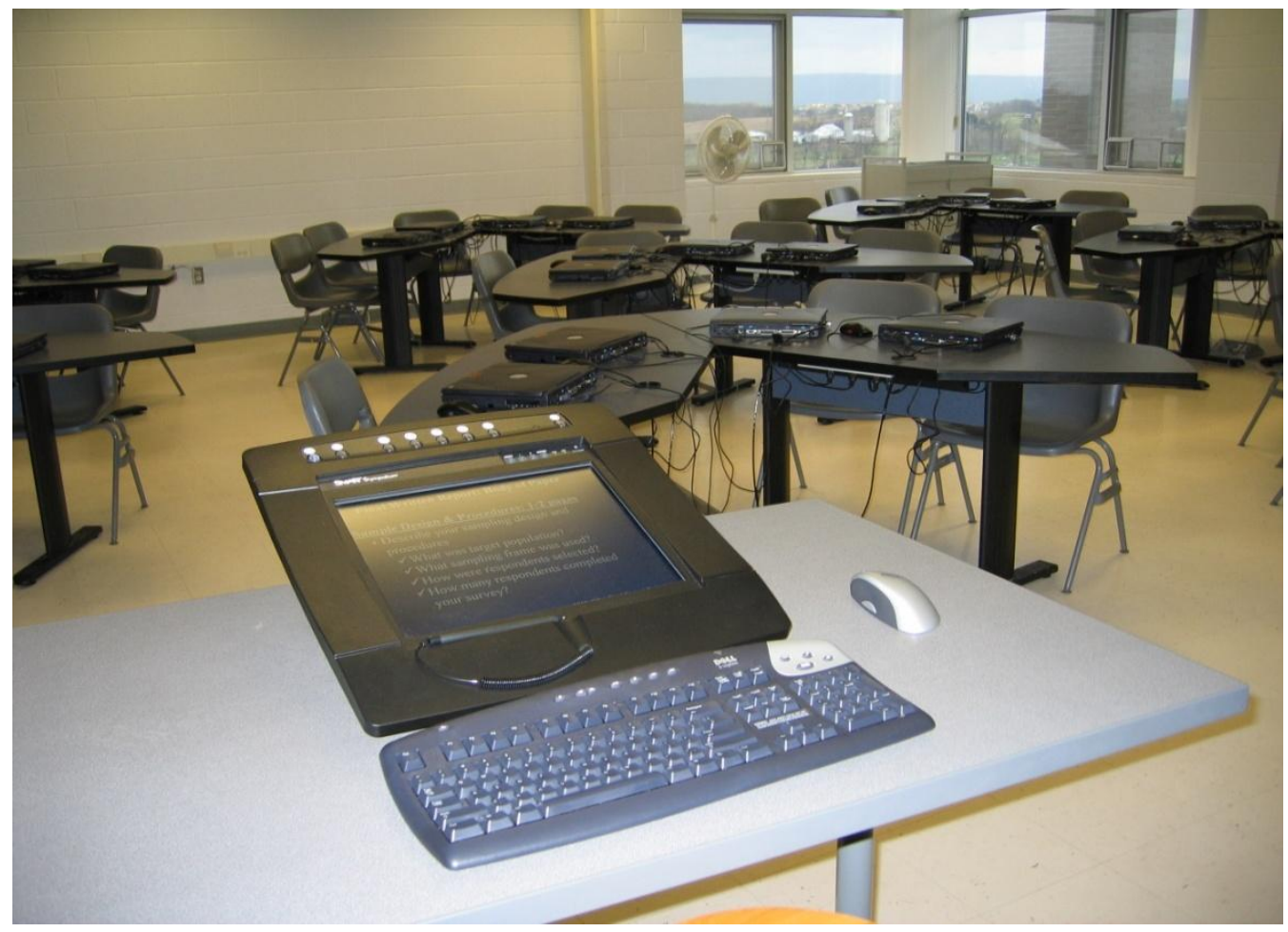

Figure 6

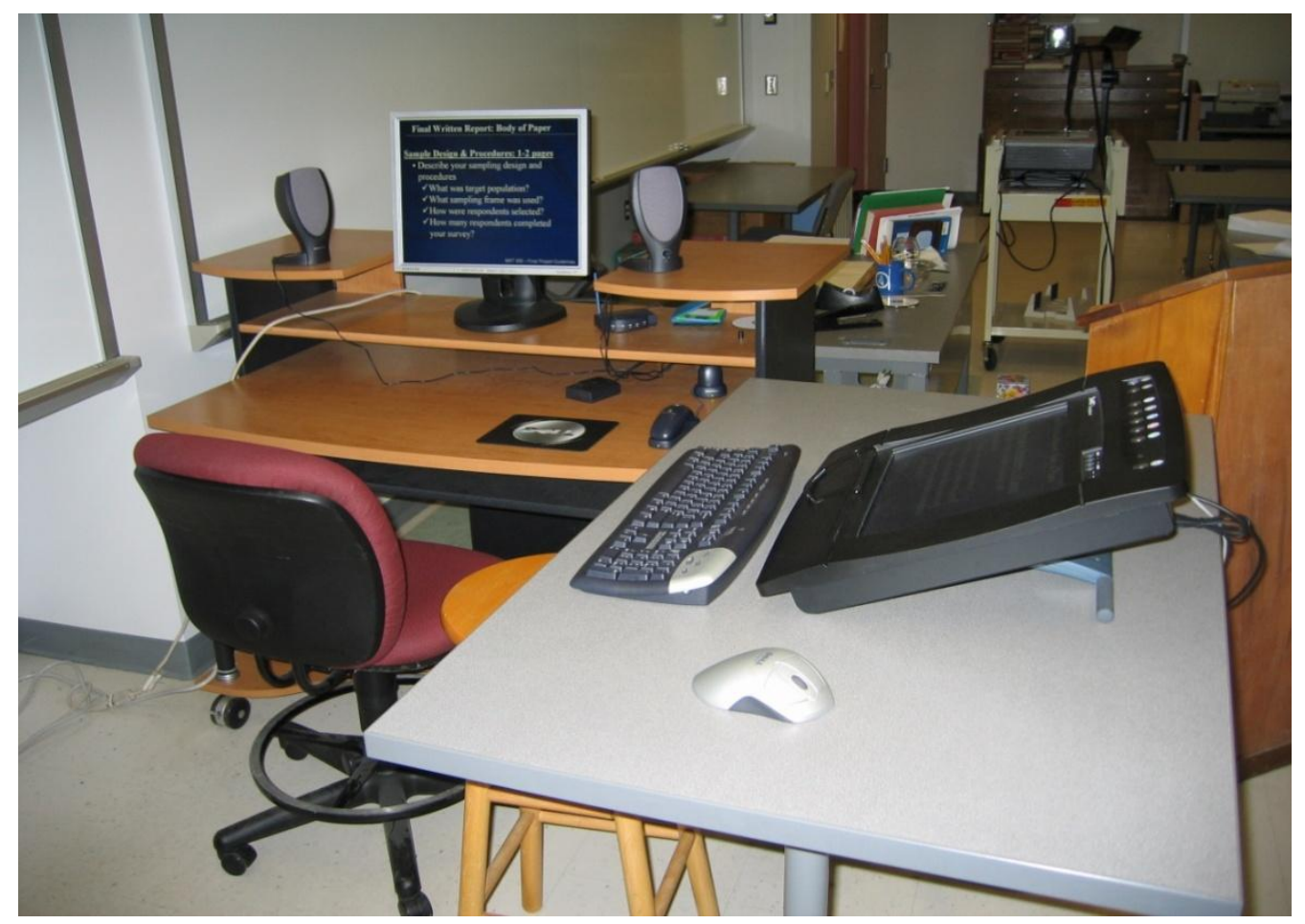

Figure 7 




Chart 1

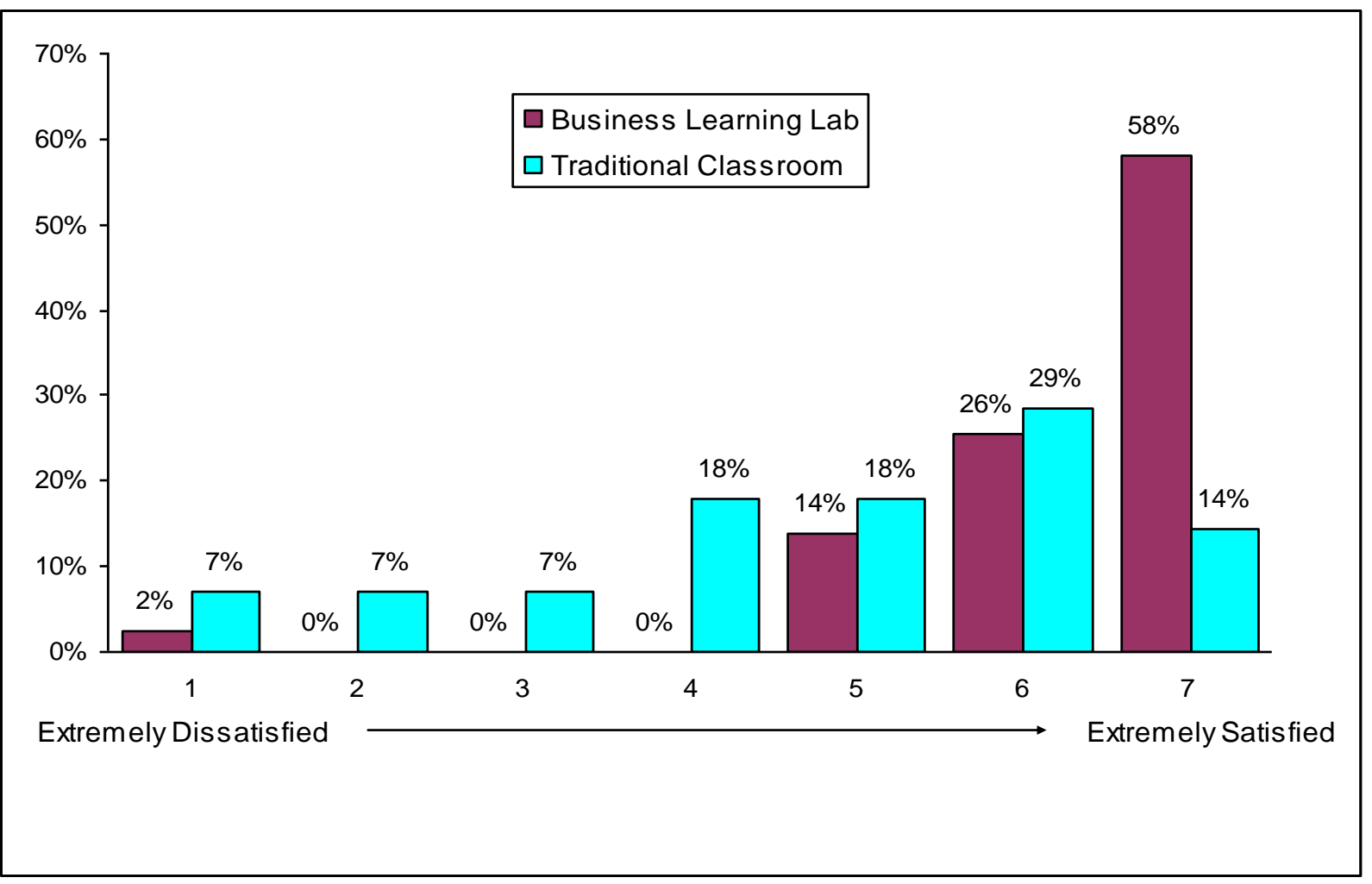

Chart 2 


\section{RECOMMENDATIONS AND LESSONS LEARNED}

The first semester's use of the BLL provided the facility's designers and users with important information about designing and using technology-enhanced classroom. Comments and suggestions regarding various aspects of the facility are included below.

\section{WORKSTATIONS/CONFERENCE TABLES}

The workstation tables' size and shape worked as planned. They were large enough to accommodate a laptop, textbook, and a writing surface while retaining a sense of community for the students at each table. The tables as installed consist of two attached units. They can easily be disassembled to stand as single units or a third unit incorporated forming a roughly circular conference table.

\section{SECURITY CONCERNS}

Several security enhancements were added as the use of the lab changed. To make the facility available for as many hours as possible, including evenings and weekends, two security features were added. Two security cameras were included into the classroom. A brief faculty discussion ensued regarding how they might be used to evaluate faculty performance and general privacy issues. The camera system is set up to alternate between two cameras, is primarily oriented towards the entrances to the room and workstations, and includes no audio. Faculty and administrators that viewed videos taken during typical class times and all were satisfied that the output was unusable for anything but security identification purposes.

Laptops are also locked to the tables with security tables. These allow the computers to be moved on the desktops but prevent thefts of opportunity. Instructors that use the classroom are provided a master key to the computer locks, which allows the laptops to be unlocked quickly and easily for use as appropriate.

Three computer security carts are available for longer terms storage, such as during semester breaks, or for easy transport to other classrooms. An important lesson learned from a previous experience is that one large laptop security cabinet for 32 computers is too heavy and unwieldy. Three 15 unit carts proved to be much more manageable.

\section{WIRELESS NETWORK}

The room selected for the Business Learning Lab was not originally planned to be a technology classroom. As a result the number of Ethernet outlets was minimal and poorly located for a wired classroom. Current bandwidth technology is adequate but not optimal; ideally, a hardwired network is preferable. Most of the difficulty was attributed to the classroom management software. Installing additional access points and a sub-network just for the classroom management software solved the vast majority of network overload problems.

\section{SYNCHRONEYESTM, THE CLASSROOM MANAGEMENT SOFTWARE}

SynchronEyes ${ }^{\mathrm{TM}}$ has proven to be a major supporting software technology for teamwork activities. Its many features allow a wide range of control directly from the instructor's station. With regard to teamwork, the software allows groups to be formed, any group's or student's screens to be view through the LCD projector, and the ability of the instructor to remotely control any laptop. Two favorite features of instructors are the ability to monitor the activities on all computers at once and the ability to blank out all students' screen and freeze all computers with a single mouse click. Setting up the software on the sub-network required considerable technical expertise and glitches, such as one or two computers not registering in the management system, still occur but overall the teamwork experience would not be as successful as it has been without it. 


\section{PROJECTORS AND DISPLAYS}

A strong recommendation is not to scrimp on projectors. While it is tempting to cut costs here because of the wide range of prices and sizes, it will be in your best interest to purchase a top-of-the-line system. A critical feature is the brightness, measured in lumens. Turning out the lights to view the screen has a well-known effect on students' eyelids. We elected to install a rather large $(18 \mathrm{lb})$ Panasonic LCD with a 3700 lumen output. Its output is bright enough to enable the lights to remain on and window shades open. The resolution quality is sufficient to show video and DVD with excellent clarity.

A 50-inch plasma display is also incorporated into the classroom technology. We opted for mounting it as a self-contained unit on a movable stand. This turned out to be a good choice because it is not used daily and can easily be transported to other classroom. However, having a second display unit available is an important feature since dual displays during presentations, especially multimedia, are becoming commonplace.

\section{SOUND SYSTEM}

On the advice of several students a sound system was integrated into the ceiling. Student noted that using speakers integral to the instructor's computer, plasma, or TV are too loud to students near the speakers while just audible to students distant from the speakers. By installing a sound system in the ceiling, balancing and modulating sound to appropriate levels is a simple operation. Lavaliere microphones with a belt-attached remote amplifier are available. Students enjoy trying these out during presentations; it made them "feel so professional."

\section{INSTRUCTOR'S STATION}

The students are not the only ones who enjoy high tech instructional technology. The instructor's station includes a high end Dell desktop system. In addition to the typical peripherals, a Sympodium ${ }^{\mathrm{TM}}$ (www.smarttech.com) unit is included. This device acts as a miniature interactive whiteboard, with capabilities similar to tablet computers. The instructor can stand (or sit) at the device while facing the class and annotate whatever is on the screen. Using a wireless remote mouse and keyboard enhance the capabilities and ease of use. The display is WYSIWYG (what you see is what you get), that is, the instructor's annotations show up directly on the screen and can even be saved for future use.

A small but useful addition to the station is a motion sensing remote mouse. (http://www.gyration.com) It works like a traditional mouse but the instructor can manipulate the cursor on the screen with hand, arm, and finger movements from anywhere in the classroom.

\section{PERIPHERALS}

Other technologies available in the lab include a high-speed black/white laser printer, a color laser printer, a scanner, a digital camera, and a digital camcorder. All of these are available to students, albeit limitations have had to be installed on the printers.

\section{FACULTY TRAINING}

All faculty who used the facility during the first semester it was available felt comfortable with the majority of technology after an hour or less of informal training and experimenting. The primary difficulties occurred when including multimedia into lectures and discussions because input/output configurations of the equipment. Future technology-enhanced classroom should include integrated control system similar to the product lines of Crestron (http://www.crestron.com) or AMX (http://www.amx.com)

\section{STUDENT TRAINING}

Very little student training was required as they immediately became active experimenters with the technology and quickly became proficient users. Using network printers and CD/DVD burners presented the most problems but these were solved with a simple one-page handout of instructions. 


\section{CONCLUSION}

This technology-enhanced classroom/lab is a single but important iteration in provide the most meaningful educational experience to students. The College is planning facilities that focus on a formal presentation environment and videoconferencing. The lessons learn during the design and implementation of the Business Learning Lab will make designing future facilities quicker, better, and more cost effective.

\section{ACKNOWLEDGEMENTS}

This activity is supported in part by funds from the Commonwealth of Pennsylvania.

\section{AUTHOR INFORMATION}

Dr. Michael T. Marsh, a member of the Shippensburg faculty since 1991, is a Professor of Management Information Systems at the John L. Grove College of Business, Shippensburg University. His academic credentials include a B.S. in Mathematics, a M.S. in Computer Science, an MBA, and a doctorate in Operations Research. He is a university leader in the use of instructional technology and taught a variety of classes including Business Computer Systems, Computer Programming, and Instructional Technology. Dr. Marsh has written and been the project director for several successful technology grants and serves on the University Emerging Technology Committee.

Dr. Ronald K. Taylor is a Professor of Marketing at the John L. Grove College of Business, Shippensburg University. His academic credentials include a B.S. and a M.S. in Business \& Education, and a Doctorate in Marketing. His teaching and research interests are in marketing education, marketing management \& strategy, retail and sales management. His research has been published in a variety of journals. He consults in the retail and sales management areas and sits on the board of directors for several professional and nonprofit organizations.

Dr. Stephen J. Holoviak has been serving as the Dean of the John L. Grove College of Business at Shippensburg University for the past ten years. Prior to this he was a faculty member in the management/marketing department for eighteen years. During his tenure at Shippensburg University he directed the H.R. Frehn Center for Management, a research and consulting outreach arm of the College of Business. Dr. Holoviak is the author/coauthor of six books and over 150 referred publications and the former contributing editor of the Human Resource Management Report magazine.

\section{REFERENCES}

1. Dugan, Robert F., et al. (1998), Exploring Collaborative Learning in Rensselaer's Classroom-in-the-Round, Rensselaer Polytechnic Institute Technical Report 98-1, http://www.cs.rpi.edu/tr/98-1.pdf, retrieved February 15, 2008.

2. Manning, Linda M. \& Riordan, C.A (2000), Using Groupware Software to Support Collaborative Learning in Economics. The Journal of Economic Education, 31 (3), 244-252.

3. Robinson, Stephen P. (2001), Organizational Behavior, $9^{\text {th }}$ ed., (Upper Saddle River, NJ: Prentice Hall). Chapter 8

4. Rogers, Edwin H. \& Geisler, C. (1997), A Collaborative Learning Environment for Intellectual Teamwork Across the Curriculum. ASEE/IEEE Frontiers in Education Conference Proceeding, http://fie.engrng.pitt.edu/fie97/papers/1491.pdf retrieved February 15, 2008.

5. Schellhardt, T.D., (1994), To Be a Star among Equals, Be a Team Player, Wall Street Journal, April 20, 1994, pB1.

6. Scholtes, Peter R, et. al. (1996), The Team Handbook, $2^{\text {nd }}$ Ed. (Madison, WI: Oriel Incorporated) 